Document downloaded from:

http://hdl.handle.net/10251/64682

This paper must be cited as:

Belenguer Martínez, A.; Borja, A.; Esteban González, H.; Boria Esbert, VE. (2015). HighPerformance Coplanar Waveguide to Empty Substrate Integrated Coaxial Line Transition. IEEE Transactions on Microwave Theory and Techniques. 63(12):4027-4034. doi:10.1109/TMTT.2015.2496271.

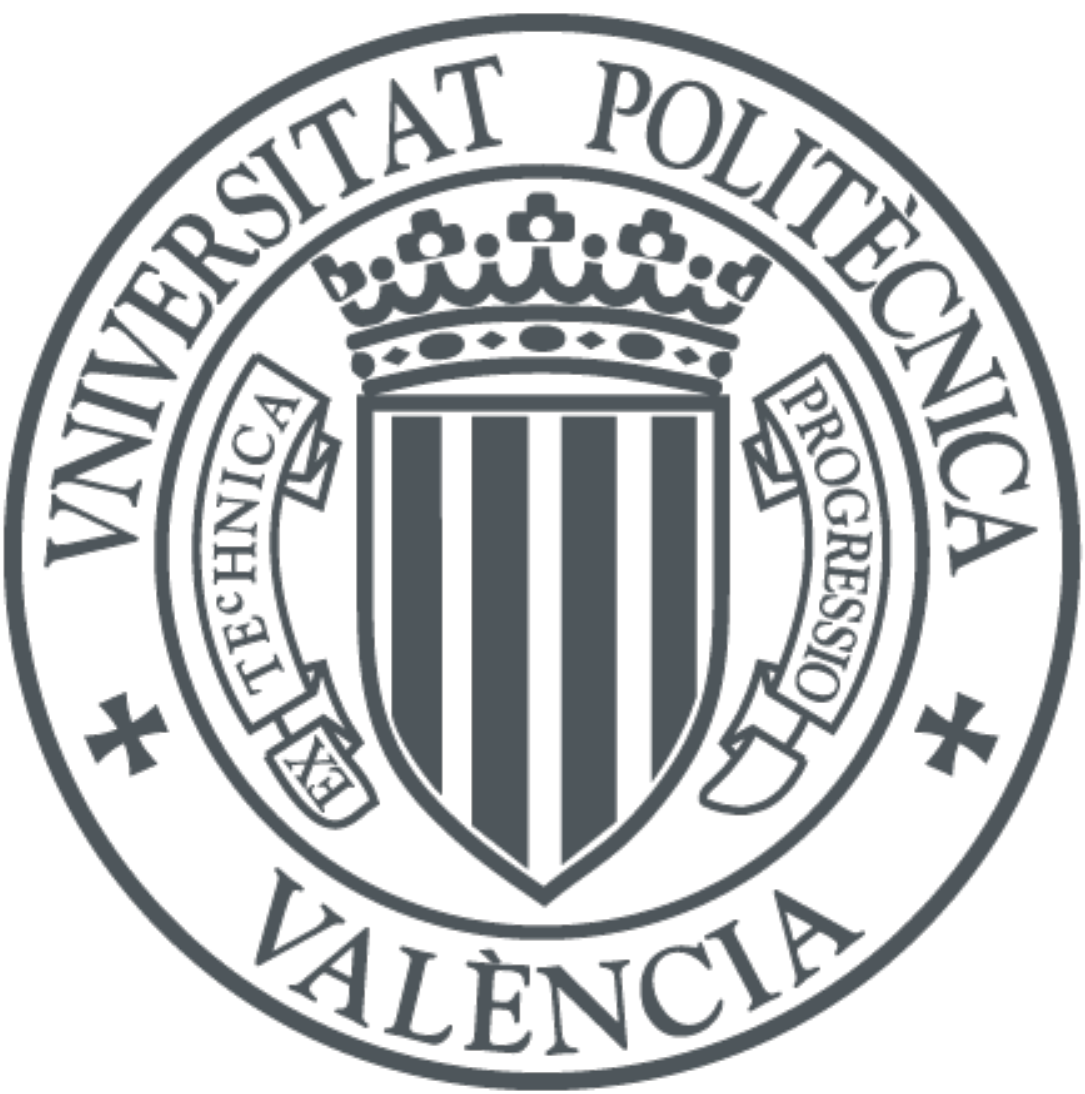

The final publication is available at

http://dx.doi.org/10.1109/TMTT.2015.2496271

Copyright Institute of Electrical and Electronics Engineers (IEEE)

Additional Information 


\title{
High-performance Coplanar Waveguide to Empty Substrate Integrated Coaxial Line Transition
}

\author{
Angel Belenguer, Senior Member, IEEE, Alejandro L. Borja, Member, IEEE, \\ Hector Esteban, Senior Member, IEEE, and Vicente E. Boria, Senior Member, IEEE
}

\begin{abstract}
Very recently, a new empty coaxial structure, entirely built with printed circuit boards, has been proposed. The resulting coaxial line has low radiation, low losses, high quality factor, mono-mode propagation and is non-dispersive. Also, and conversely to other coaxial line designs, the fabrication process of this empty coaxial line permits to easily adjust the dimensions of the inner and outer conductors. Thus, the response of the coaxial line can be tailored by designing the shape of the conductors appropriately. Up to now, this novel coaxial line has not been successfully integrated in a planar substrate, since a working transition to a traditional planar line has not been defined yet. Therefore, in this paper, a novel and high-quality transition from coplanar waveguide to this new and versatile empty coaxial line is proposed. With this transition, the coaxial line is completely integrated in a planar circuit board, so that it truly becomes an empty substrate integrated coaxial line. The proposed transition has been fabricated and assembled. Both full-wave simulated and measured results show an excellent agreement. Therefore, the proposed transition is suitable to develop completely substrate integrated planar components for applications in wideband communication systems that require very high-quality responses and protection from external electromagnetic interferences. In order to show this fact, this new transition has been applied to integrate a high-performance empty coaxial line filter in a planar substrate. The measured response of this filter is excellent, and proves the goodness of the proposed transition that has enabled, for the first time, the complete integration of an empty coaxial line in a planar substrate.
\end{abstract}

Index Terms-Empty substrate integrated coaxial line, ESICL, substrate integrated coaxial line, SICL, substrate integrated waveguide, SIW, substrate integrated circuit, SIC, bandpass filter.

\section{INTRODUCTION}

I INTEGRATION of microwave/RF components in communication systems is of key importance to design and fabricate circuits with small size, low weight, low cost, high reliability, easy assembling and possibility of mass production. Full system integration is therefore playing an important role in current telecommunication developments. As a consequence, a great deal of effort has been dedicated to propose novel devices in planar technology. Some years ago, Deslandes and $\mathrm{Wu}$ [1] presented in 2001 an initial research work that

This work was supported by the Ministerio de Ciencia e Innovación, Spanish Goverment, under Research Projects TEC2013-47037-C5-3-R and TEC2013-47037-C5-1-R.

A. Belenguer and A. L. Borja are with Departamento de Ingeniería Eléctrica, Electrónica, Automática y Comunicaciones, Universidad de CastillaLa Mancha, Escuela Politécnica de Cuenca, Campus Universitario, 16071 Cuenca, Spain (e-mail: angel.belenguer@uclm.es)

H. Esteban and V. E. Boria are with Departamento de Comunicaciones, Universidad Politécnica de Valencia, 46022 Valencia, Spain (e-mail: hesteban@dcom.upv.es). gave and is giving rise to a vast number of new substrate integrated components. In this study, a novel concept for substrate integrated waveguide (SIW) transmission line was presented. The structure proposed employed rods of metallic via holes to confine a propagating wave between the upper and bottom plates of a substrate layer. By this mean, the vertical dimension of conventional 3D waveguide transmission line can be reduced. Thereafter and based on this former study, several solutions including filters [1]-[10], antennas [11]-[16], transitions and tapers [17]-[19], baluns [20], [21], couplers [22]-[25] and new transmission lines [26]-[30] were proposed. Among all these works, it is of interest the excellent properties of substrate integrated coaxial lines (SICL) reported in [30]. This transmission line was shown to have single mode propagation, non-dispersion and low radiation. Due to these properties, this sort of coaxial line can be suitable for applications with wider bandwidth responses and lower losses than other proposed substrate integrated circuits. For instance, wideband filters [31], [32], couplers [33], [34], baluns [35] and power dividers [36] have been designed using SICLs.

In all the aforementioned structures, the substrate integrated design offers a range of benefits in comparison with conventional 3D waveguide and coaxial transmission lines. However, the losses introduced by the dielectric permittivity of the substrate limit the use of these devices, specially as frequency is increased. This fact was clearly demonstrated in the work presented by Belenguer et al. [37]. In this particular case, the proposed structure called empty substrate integrated waveguide (ESIW) showed significantly lower insertion loss than SIW for two bandpass filter designs working at different frequencies. In addition, it was also shown that the quality factor is increased around 8 times due to the absence of dielectric material.

Following the same idea, in [38] an empty coaxial line is proposed. This coaxial line is built using printed circuit boards (PCBs), but, strictly speaking, it is not integrated in a dielectric substrate since, in this work, it has not been proposed a transition to, at least, one traditional planar transmission line: microstrip, coplanar waveguide, stripline, etc. [39]. However, the complete integration of this empty coaxial line is of great interest for developing integrated high-quality, low-cost and shielded microwave devices. Therefore, we present in this paper a transition from grounded coplanar waveguide (GCPW) to this new empty coaxial transmission line. The integration of a coaxial line into a partially empty substrate permits to obtain non-dispersive and shielded lines with low loss, low radiation and suitable for wideband applications. Microstrip or coplanar 
lines are low cost and straightforward to fabricate, but are not shielded and exhibit radiation losses and cross-talk problems. On the other hand, striplines present lateral leakage in addition to cross-talk. The proposed coaxial topology solves these drawbacks and combines the advantages of coaxial cables and planar transmission lines. Also, it permits to easily control the dimensions of the coaxial line. As a result, the impedance of the line can be adjusted modifying the widths of the inner and outer conductors, or even loading these conductors with inductive/capacitive elements as well as tunable components to obtain reconfigurable responses. The proposed design has the advantage of fast full-wave simulation as a PEC background material can be used during calculations. This is not possible for open structures, where a radiation boundary condition is necessary. As it will be shown, this fact considerably reduces the computation time, which is of great importance during optimization processes (e.g. for design purposes).

To show one possible application of the proposed transition to this new empty substrate integrated coaxial line (ESICL), a wideband bandpass filter is designed and fabricated. In this regard, it is important to note that this bandpass filter response cannot be obtained with SIW/ESIW structures, and has several advantages compared to microstrip, coplanar or stripline filters such as non-radiation, non-dispersion, non-crosstalk, faster simulation and lower insertion loss. The proposed coaxial line has a wide range of potential applications. For instance, communication systems incorporating services that operate in a wideband and that requires protection from external electromagnetic interferences.

The paper is organized as follows. Section II presents the layout and design of the coaxial line. Section III presents a high-performance GCPW to ESICL transition. The response of a bandpass filter prototype is shown in Section IV. Finally, the main conclusions of the work are discussed in Section V.

\section{ESICL ASSEMBLING AND PERFORMANCE}

At least three substrate layers plus two covers, which close the whole structure, are required to fabricate an ESICL (see Fig. 1). One or more inner layers, which must be separated from the covers by, at least, one substrate layer, sustain the internal conductor of the coaxial line as it is shown in Fig. 1. The covers can be manufactured by simply using thin metallic sheets, or they can be built using two additional substrate sheets, which would allow to integrate external circuitry or lumped elements that could interact with the ESICL device. The different layers of this structure can be of different thickness and material. They can be assembled by pressure or welding, providing, in any case, excellent results.

In order to evaluate the performance of the ESICL, in Tab. I, the losses of an ESICL are compared, at $15 \mathrm{GHz}$, with the losses of several copper transmission lines: microstrip, GCPW, SIW, ESIW and rectangular waveguide (RWG). The dimensions for all of the compared lines are also shown in Tab. I. These dimensions have been determined considering the following facts: the planar lines have been devised for a Rogers $4003 \mathrm{C}$ substrate of $0.813 \mathrm{~mm}$ thickness and $35 \mu \mathrm{m}$ of metallization, the QTEM/TEM lines have been designed

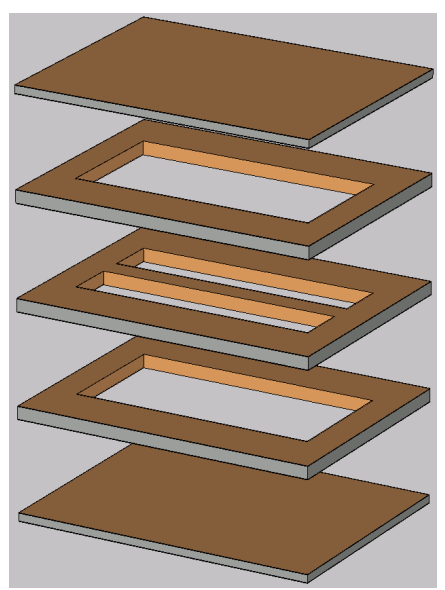

(a) Separated layers 3-D view

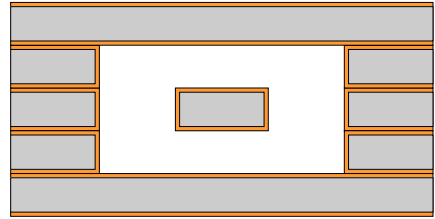

(b) Cross-section
Fig. 1. Simplest construction of an ESICL (three inner substrate layers plus two covers).

TABLE I

SIMULATED LOSSES AND UNLOADED $Q$ FACTORS OF SEVERAL WELL-KNOWN TRANSMISSION LINES AND ESICL.

\begin{tabular}{clcc} 
Line & Dimensions & Losses $(15 \mathrm{GHz})$ & $Q_{u}(15 \mathrm{GHz})$ \\
\hline RWG & $\begin{array}{l}a=15.7988 \mathrm{~mm} \\
b=7.8994 \mathrm{~mm}\end{array}$ & $0.17 \mathrm{~dB} / \mathrm{m}$ & 6095.3 \\
\hline ESIW & $\begin{array}{l}a=15.7988 \mathrm{~mm} \\
b=0.933 \mathrm{~mm}\end{array}$ & $1.07 \mathrm{~dB} / \mathrm{m}$ & 1476.5 \\
\hline SIW & $\begin{array}{l}a=8.3851 \mathrm{~mm} \\
b=0.933 \mathrm{~mm}\end{array}$ & $11.06 \mathrm{~dB} / \mathrm{m}$ & 289.52 \\
\hline Microstrip & $w_{\text {strip }}=1.97 \mathrm{~mm}$ & $7.79 \mathrm{~dB} / \mathrm{m}$ & 23.04 \\
\hline GCPW & $\begin{array}{l}\text { see feeding line } \\
\text { in Fig. } 3\end{array}$ & $9.23 \mathrm{~dB} / \mathrm{m}$ & 151.81 \\
\hline \multirow{2}{*}{ ESICL } & $\begin{array}{l}w_{\text {inner }}=1.917 \mathrm{~mm} \\
h_{\text {inner }}=0.933 \mathrm{~mm} \\
w_{\text {outer }}=6 \mathrm{~mm} \\
h_{\text {outer }}=2.799 \mathrm{~mm}\end{array}$ & $0.9 \mathrm{~dB} / \mathrm{m}$ & 1620.4 \\
\hline
\end{tabular}

to exhibit a characteristic impedance of $50 \Omega$, and, finally, the waveguides have been designed to match the desired bandwidth, from 12 to $18 \mathrm{GHz}$.

Additionally, in order to provide a more exhaustive comparison of the performance of these lines, the unloaded $Q$ factor of a $\lambda / 2$ resonator has been also estimated. To perform this analysis, a piece of the lines of Tab. I, of length approximately equal to $\lambda / 2$, has been tightly coupled to identical feeding lines, so that the desired resonator has been obtained. A capacitive gap has been used to couple the feeding lines and the resonator for the QTEM/TEM lines, i.e. microstrip, GCPW and ESICL, while an inductive iris has been used to couple the feeding lines to the resonator for the waveguides, i.e RWG, ESIW and SIW. These resonators have been simulated with a full-wave simulator, and then the unloaded $Q$ factor has been estimated applying the following formula [40],

$$
Q_{u}=\frac{\frac{f}{f_{H}-f_{L}}}{1-10^{-I L / 20}}
$$

where $f$ is the resonant frequency ( $15 \mathrm{GHz}$ in this case), $f_{H}-$ $f_{L}$ is the half-power bandwidth, and IL is the insertion loss at the resonant frequency. 
The performance of the ESICL is comparable to ESIW, quite close to the performance of the rectangular waveguide, and much higher than the performance of classical planar lines like microstrip or GCPW, or even SIW, which is considered a high-performance planar line. Therefore, very high quality devices can be designed using this novel and promising transmission line.

\section{GCPW-TO-ESICL TRANSITION}

Without a proper transition to a traditional planar line, the usefulness of the ESICL is very limited. Therefore, in this section, a high-quality transition to a GCPW line has been designed [41]. In Fig. 2, a 3D-view of this new transition without covers is shown. In this figure it can be seen that,

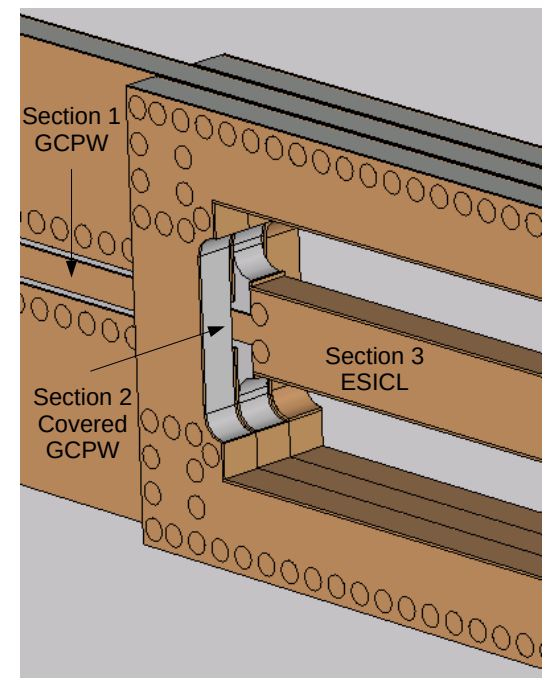

Fig. 2. 3-D detail of a complete GCPW-to-ESICL transition without covers.

globally, the transition consists of three different sections. The first section is simply the GCPW feeding line. The second section is also a GCPW line, but, in this case, covered with a dielectric and a metallic housing. Finally, the third section is the ESICL itself.

In Fig. 3, it can be seen the top and bottom view of the transition for the central substrate layer, which sustains the inner conductor of the coaxial line. In this figure, only the separation between the vias surrounding the coplanar waveguide has been specified, $p_{\text {cop }}$. The other vias simply shield the structure and they barely affect the response of the transition. Therefore, it is not necessary to give a fixed value for their separation, $p$. Its actual value depends on the width of the substrate layer for the vertical rows of vias, and the length of the ESICL for the horizontal rows. Nevertheless, $p$ is always chosen as close as possible to $p_{\text {cop }}$.

In Fig. 4 it is shown the layout of the substrate sheet that is placed above the main substrate layer of Fig. 3. In this layer, the transition is quite simpler. A frame around the hole that defines the coaxial line is necessary in order to provide mechanical stability to the whole structure. Due to this necessary frame, the line that crosses below it, in the central layer, becomes a CGPW covered with dielectric and

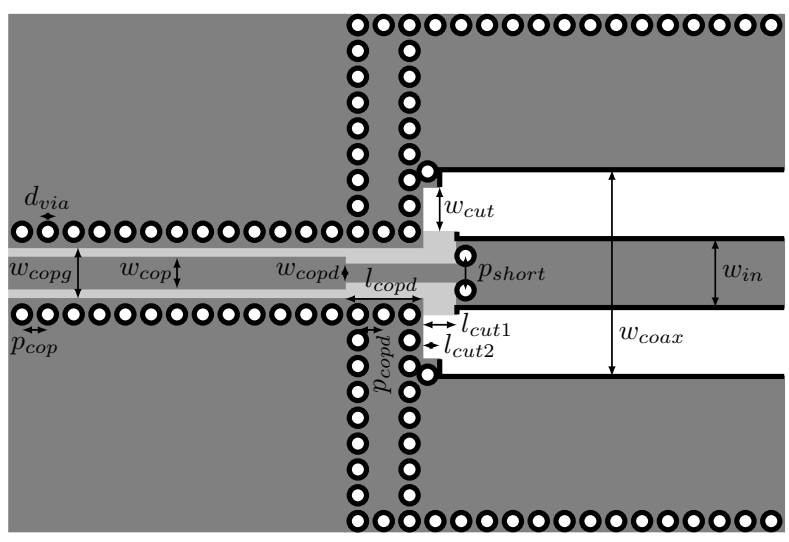

(a) Top

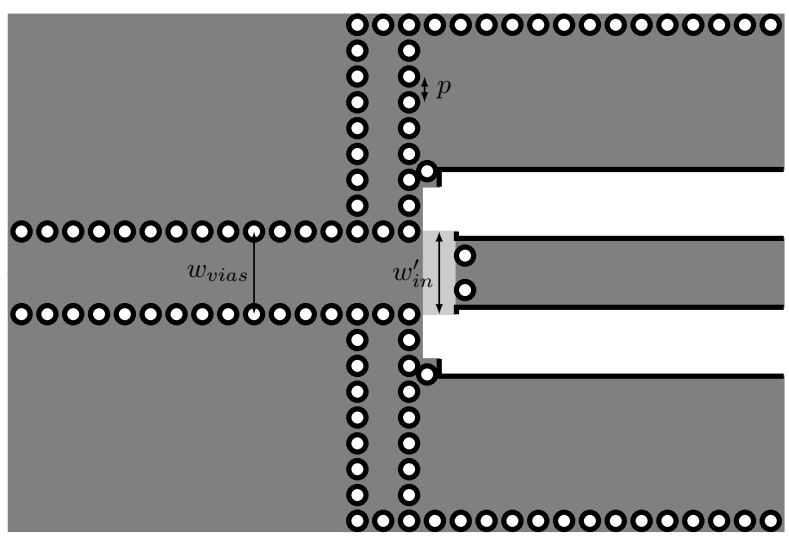

(b) Bottom

Fig. 3. GCPW-to-ESICL transition in the central layer. Dark gray is metal covering the substrate. White represents holes emptied in the substrate. Light gray stands for substrate without metallic cover. Black represents the metallization along substrate edges.

metal, leading to the second section of the transition. In order to keep the same line impedance in this second section of the transition, the central strip of the covered GCPW, is slightly narrower than the central strip of the conventional GCPW feeding line.

In Fig. 5, one can see the transition in the lower layer, which is the simplest one. In this case a frame of dielectric material is also necessary to provide the structure with the necessary mechanical stability. However, in this case, the presence of this external frame has no consequence from the electromagnetic point of view.

Finally, an specific transition has been designed. This transition has been optimized for a Rogers $4003 \mathrm{C}^{\mathrm{TM}}$ substrate $\left(\epsilon_{r}=\right.$ $3.55,0.813 \mathrm{~mm}$ thickness and $35 \mu \mathrm{m}$ of copper metallization). In this case, all of the layers that form this structure have been implemented using the same substrate, although a cheaper substrate, for example FR-4, could have been used to build the lower layer and the covers. The dimensions of the designed transition can be read in Tab. II.

The procedure followed to design this transition is quite simple. In the first place, the lines are designed separately: the feeding GCPW, the covered GCPW, and the ESICL, so that all of them have the same characteristic impedance (50 $\Omega$ in this case). The dimensions obtained in this first step are 


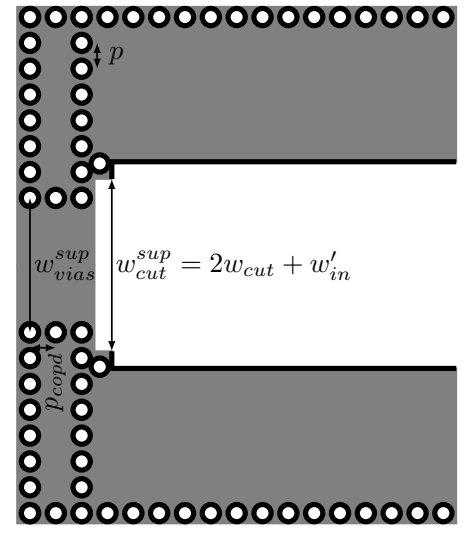

(a) Top

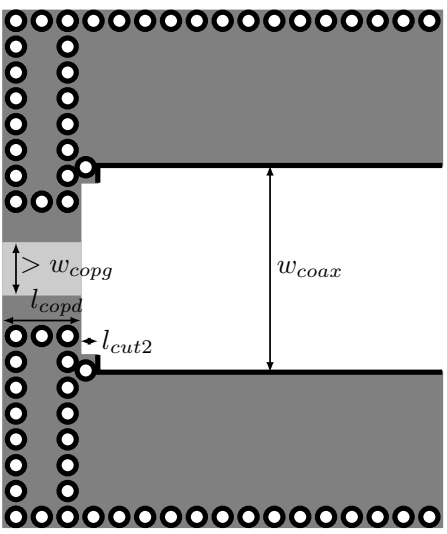

(b) Bottom

Fig. 4. GCPW-to-ESICL transition in the upper layer. Dark gray is metal covering the substrate. White represents holes emptied in the substrate. Light gray stands for substrate without metallic cover. Black represents the metallization along substrate edges.

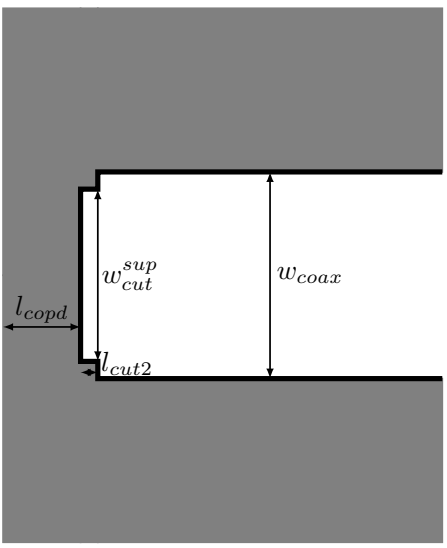

(a) Top y Bottom

Fig. 5. GCPW-to-ESICL transition in the lower layer. Dark gray is metal covering the substrate. White represents holes emptied in the substrate. Black represents the metallization along substrate edges.
TABLE II

DIMENSIONS FOR THE TRANSITION IN ROGERS $4003 \mathrm{C}^{\mathrm{TM}}\left(\epsilon_{r}=3.55\right.$, $h=0.813 \mathrm{MM})$

$\begin{aligned} d_{\text {via }}= & 0.5 \mathrm{~mm} & p_{\text {cop }}= & 0.714 \mathrm{~mm} \\ w_{\text {copg }}= & 1.014 \mathrm{~mm} & w_{\text {vias }}= & 1.914 \mathrm{~mm} \\ w_{\text {cop }}= & 0.714 \mathrm{~mm} & w_{\text {copd }}= & 0.637 \mathrm{~mm} \\ l_{\text {copd }}= & 2 \mathrm{~mm} & p_{\text {copd }}= & 0.667 \mathrm{~mm} \\ w_{\text {in }}^{\prime}= & 2.117 \mathrm{~mm} & w_{\text {cut }}= & 1.162 \mathrm{~mm} \\ l_{\text {cut } 1}= & 0.526 \mathrm{~mm} & l_{\text {cut } 2}= & 0.5 \mathrm{~mm} \\ p_{\text {short }}= & 0.806 \mathrm{~mm} & w_{\text {in }}= & 1.917 \mathrm{~mm} \\ w_{\text {coax }}= & 6 \mathrm{~mm} & w_{\text {vias }}^{\text {sup }}= & 4.44 \mathrm{~mm}\end{aligned}$

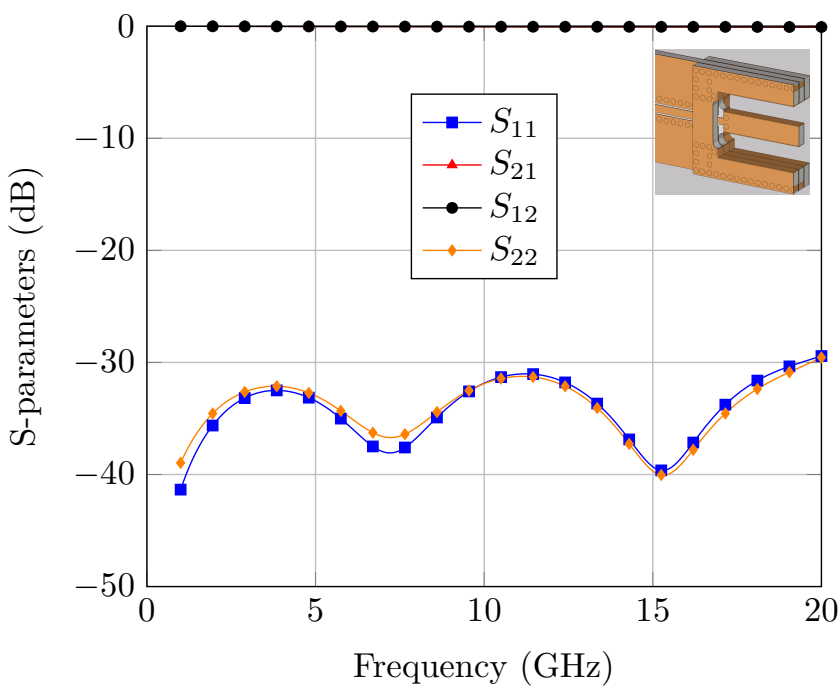

Fig. 6. Simulated response with a full-wave 3-D electromagnetic simulator of the designed GCPW-to-ESICL transition.

translated to the structure. The transition is optimized with a full 3-D electromagnetic simulator for: $w_{c u t}, w_{\text {copd }}$ y $l_{\text {cut } 1}$ so that the return losses are maximized in the band of interest (in this case from 0 to $20 \mathrm{GHz}$ ).

In Fig. 6 one can see the simulated response for the transition using a full-wave 3D electromagnetic software and considering losses. This transition exhibits an excellent response in the band of interest $(0-20 \mathrm{GHz})$ and a really low loss level $(0.07 \mathrm{~dB}$ at $20 \mathrm{GHz})$. The ESICL and this new transition are quite easy to fabricate, since only standard printed circuit board (PCB) manufacturing processes are involved in its fabrication, i.e. milling, cutting, drilling and plating. This transition has made ESICL an easily integrable transmission line in any kind of planar substrates. In Fig. 7 it is shown the back-to-back response of this transition, that is, the response of an ESICL fully integrated in a PCB. The response in the band of interest is again excellent, which confirms the high-degree of integration achieved with this new transition. Thanks to this transition, it has been possible to completely integrate an actual TEM line (not QTEM) in a planar substrate. Most of the traditional design methods conceived for planar TEM or QTEM lines (microstrip, coplanar, stripline ...) are based on the assumption that the line supports the propagation of a pure TEM mode. Therefore, they can be applied to this new transmission line, and, indeed, since this line is actually a TEM line, the results obtained will be even more 


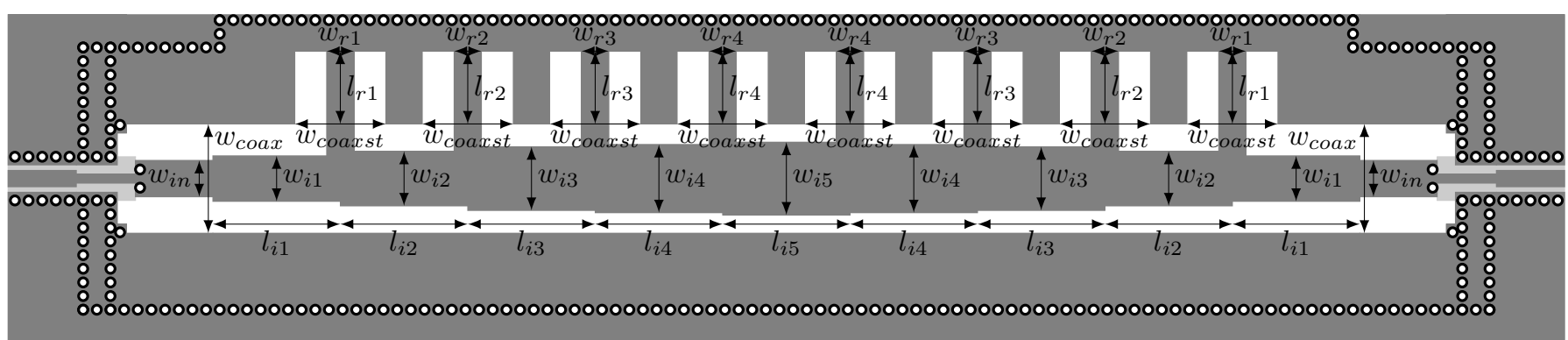

Fig. 9. Top view and dimensions for the eight cavities filter in ESICL.

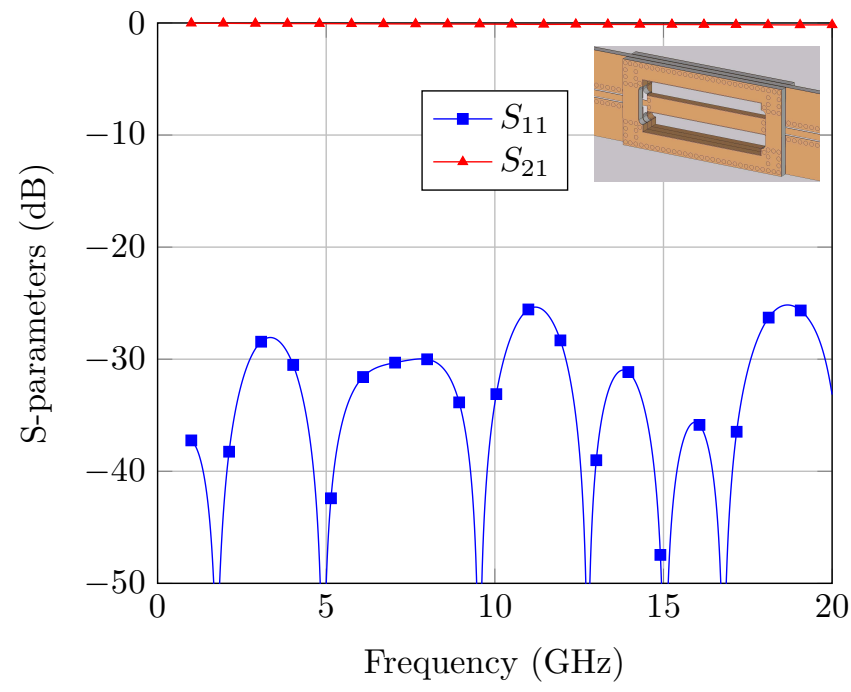

Fig. 7. Simulated response with a full-wave 3-D electromagnetic simulator of the full integration (back-to-back) of an ESICL in a PCB (GCPW feeding).

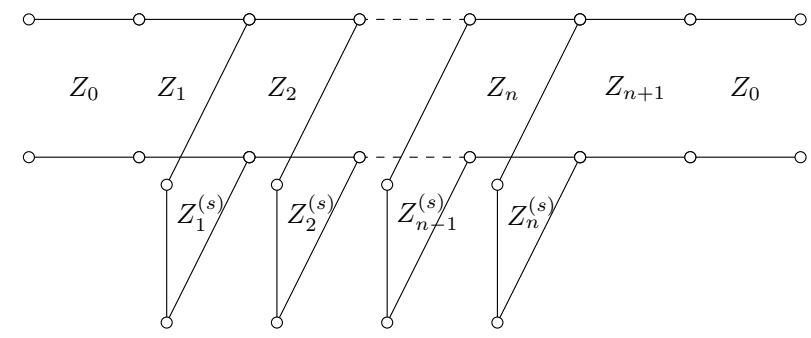

Fig. 8. Bandpass filter with shorted stubs.

accurate than the results obtained for QTEM lines. On the other hand, it is necessary to remark that ESICL is a line that exhibits very low losses. Devices implemented in ESICL, mainly those incorporating resonators, will provide very highquality responses since the ESICL resonators will have very high quality factors. The response of these new ESICL devices will be undoubtedly much better than the responses that could be obtained with any conventional planar line.

\section{BANDPASS FILTER}

In order to show the integration capabilities of the proposed transition, a real device will be fully integrated in a printed circuit board. In parallel, the performance of this real device

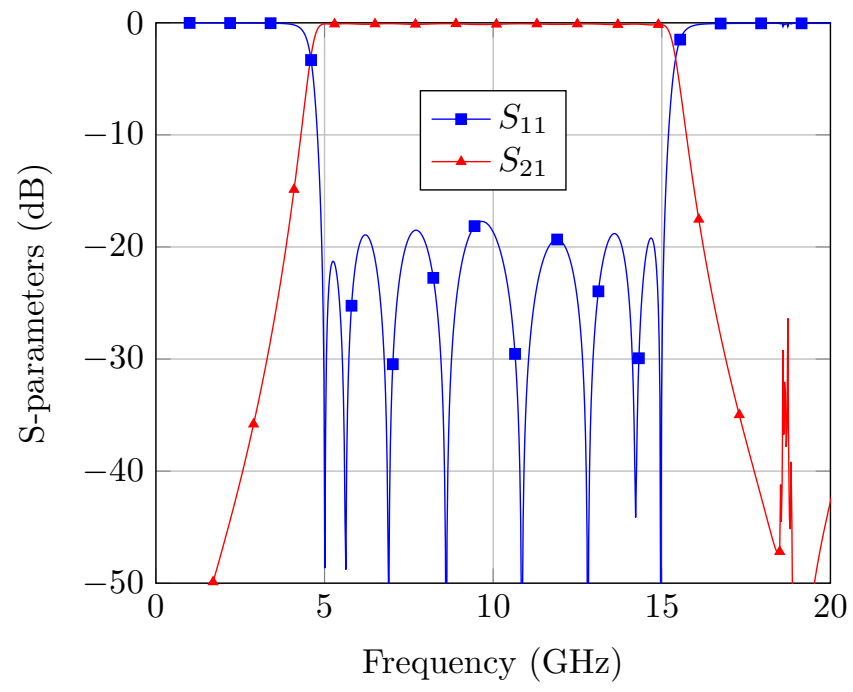

Fig. 10. Simulated response for the integrated ESICL filter.

TABLE III

DIMENSIONS FOR THE EIGHT CAVITIES FILTER IN ESICL

$\begin{array}{rlrlrl}w_{\text {in }}= & 1.917 \mathrm{~mm} & w_{\text {coax }}= & 6 \mathrm{~mm} & w_{\text {coaxst }}= & 5 \mathrm{~mm} \\ w_{i 1}= & 2.583 \mathrm{~mm} & w_{i 2}= & 3.833 \mathrm{~mm} & w_{i 3}= & 3.771 \mathrm{~mm} \\ w_{i 4}= & 3.649 \mathrm{~mm} & w_{i 5}= & 3.519 \mathrm{~mm} & l_{i 1}= & 7.446 \mathrm{~mm} \\ l_{i 2}= & 8.330 \mathrm{~mm} & l_{i 3}= & 8.109 \mathrm{~mm} & l_{i 4}= & 7.999 \mathrm{~mm} \\ l_{i 5}=7.941 \mathrm{~mm} & l_{r 1}= & 6.319 \mathrm{~mm} & l_{r 2}= & 6.432 \mathrm{~mm} \\ l_{r 3}= & 6.403 \mathrm{~mm} & l_{r 4}= & 6.396 \mathrm{~mm} & w_{r 1}= & 1.671 \mathrm{~mm} \\ w_{r 2}= & 1.683 \mathrm{~mm} & w_{r 3}= & 1.895 \mathrm{~mm} & w_{r 4}= & 1.709 \mathrm{~mm}\end{array}$

will be also evaluated, in order to remark the interest of the proposed transition, since it will allow to integrate high-quality and completely shielded devices in a traditional PCB.

Specifically, a very wide-band filter will be integrated in a Rogers $4003 \mathrm{C}$ substrate $\left(\epsilon_{r}=3.55,0.813 \mathrm{~mm}\right.$ thickness and $35 \mu \mathrm{m}$ of copper metallization). This filter exhibits a fractional bandwidth of $100 \%$, a central frequency, $f_{0}=10$ $\mathrm{GHz}$, and a passband ripple of $0.05 \mathrm{~dB}$. In order to design this filter a traditional configuration for designing wide-band bandpass filters with planar lines has been applied [42]. In this configuration, the resonators of the filter have been implemented with shorted stubs of length equal to $\lambda / 4$. These resonators have been coupled through impedance inverters, which have been synthesized with line sections of length equal to $\lambda / 4$ (see Fig. 8 ). 


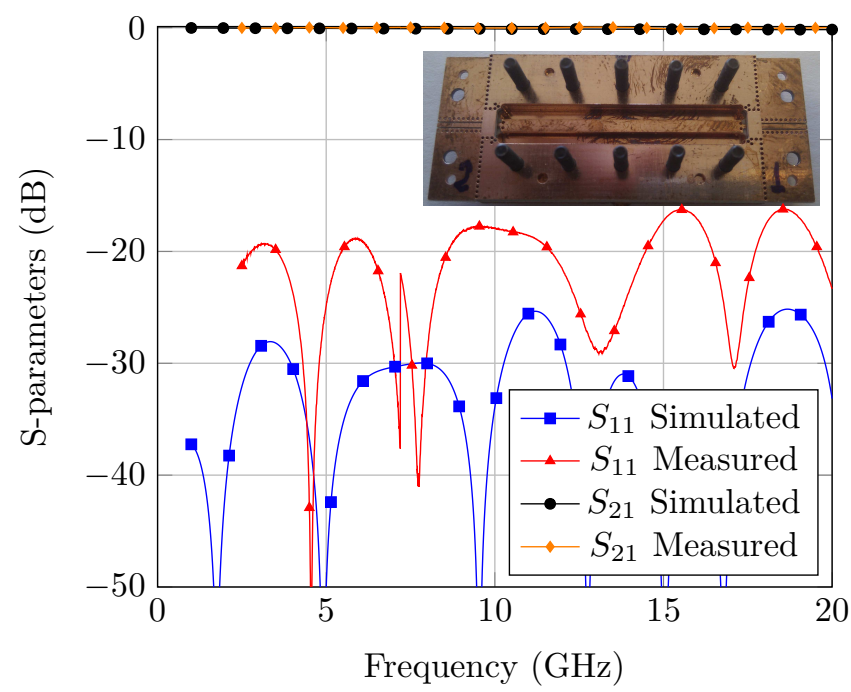

Fig. 11. Simulated response with a full-wave 3-D electromagnetic simulator vs. measurements for the back-to-back of the GCPW-to-ESICL transition.

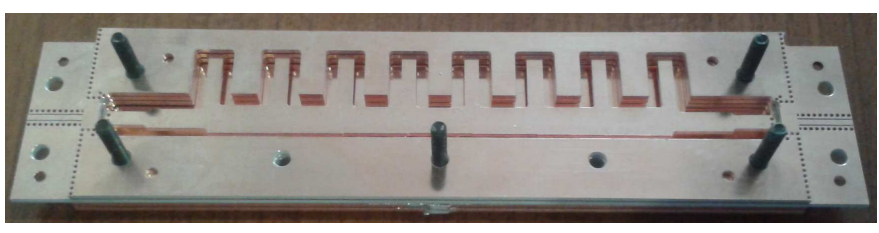

(a)

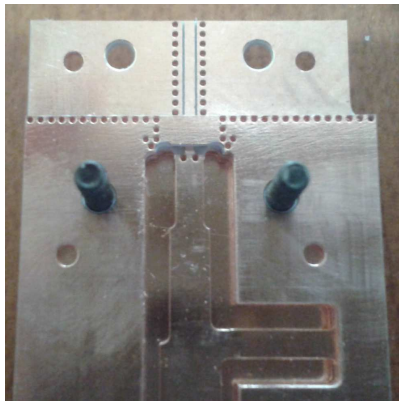

(b)

Fig. 12. (a) Photograph of the manufactured ESICL filter. (b) Detail of the transition which has been used to feed the filter prototype.

The dimensions of the filter can be seen in Fig. 9 and Tab. III. In this figure, one can see that the filter is indeed the direct implementation in ESICL of the filter of Fig. 8. This filter can be analyzed as a closed and empty structure. The size of the problem is electromagnetically small, so that it can be analyzed very fast. In this case, optimization is possible even with commercial full-wave electromagnetic software, since the optimization time becomes quite short, and, therefore, it has been possible to tune the response, which is quite similar to the response of the filter prototype.

Finally, in Fig. 10 it is shown the full-wave simulated response of this filter. These results are undoubtedly excellent, since these results consider the losses produced by the whole device. These losses are very small, only $0.14 \mathrm{~dB}$ at $f_{0}$.

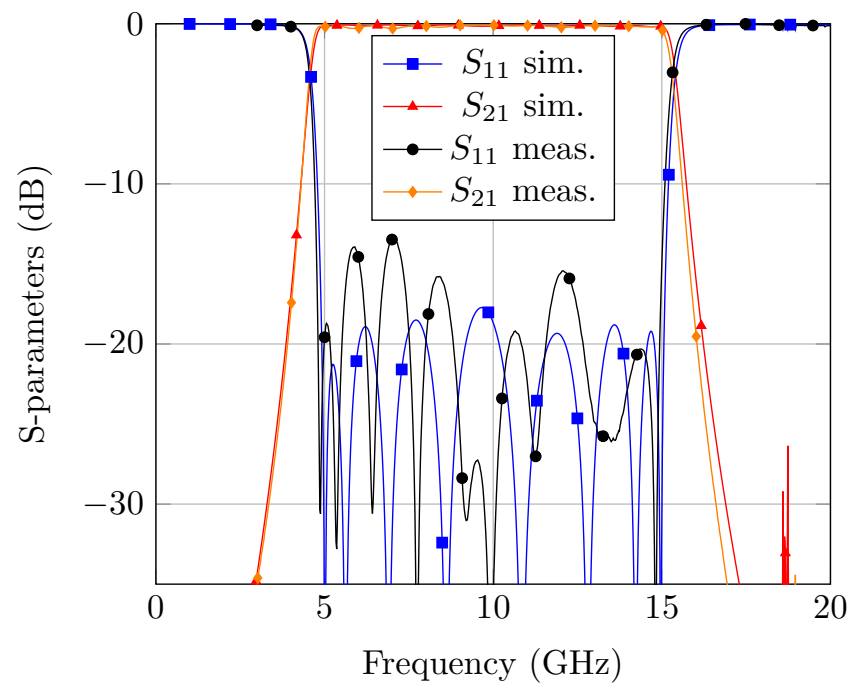

Fig. 13. Simulated response with CST (FEM solver) and measurements for the eight cavities ESICL filter.

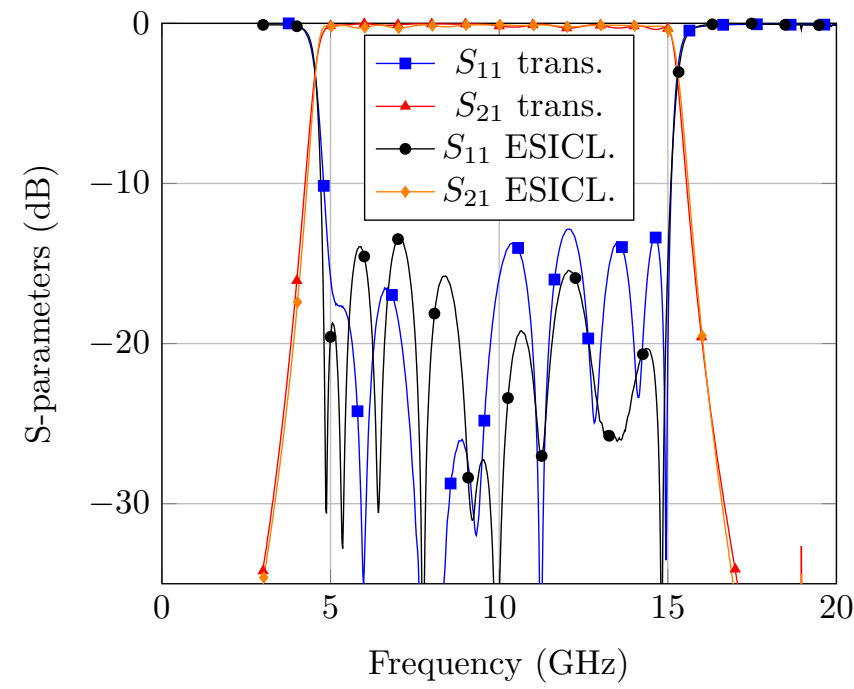

Fig. 14. Measured responses for the manufactured eight cavities filter in ESICL. Filter with transitions vs. filter without transitions.

\section{Results}

In order to experimentally verify the simulated results of the previous sections, the back-to-back configuration for the transition (Fig. 7) and the filter (Fig. 9) have been fabricated.

In Fig. 11, it can be seen a comparison between measurements and the simulated results for the back-to-back of the proposed transition. Although, due to fabrication tolerances, the measured response has deteriorated, the line is still very well integrated in the PCB and, therefore, it can be concluded that the main objective of this work has been accomplished, i.e. the full integration of the novel ESICL line in a dielectric substrate.

In Fig. 12(a) it is shown a photograph of the filter prototype without the upper cover. Besides, in Fig. 12(b), it can be seen a detailed view of one of the transitions that feed the aforementioned prototype.

Finally, in Fig. 13, one can see a comparison between 
simulations and measurements. In this figure, both results, experimental and simulated, exhibit a high degree of coincidence, although, again, the adaptation is slightly deteriorated in measurements.

In order to evaluate the real influence of the transition a last comparison is presented. In Fig. 14 measurements for the same filter are compared. On one hand, the filter has been measured de-embedding only the coaxial connectors that have been used to connect the device to the vector network analyzer (VNA). On the other hand, the same device has been measured again, but, in this case, both, the connectors and the GCPW-to-ESICL transition, have been de-embedded from measurements. Both responses have been compared in Fig. 14. Results prove that the new transition barely affects the response of the filter, i.e. both show very similar levels of return loss (around 15 $\mathrm{dB})$ and insertion loss $(0.09 \mathrm{~dB}$ without transitions and 0.16 $\mathrm{dB}$ with transitions). This fact validates again the transition, and confirms that the main objective of this work has been accomplished, since this new ESICL devices can be easily integrated in a traditional PCB.

\section{Conclusions}

The ESICL is a novel structure that can be entirely fabricated with standard dielectric substrate layers, and exclusively using PCB standard manufacturing procedures. This structure shows very interesting properties, i.e. low-loss, non-dispersion, immunity to interferences or cross-talk, etc., which makes it very attractive for developing high-quality passive or active devices. In this paper, for the first time, a high-performance transition from a traditional planar transmission line, a GCPW, to the novel ESICL has been designed. As a result, the promising ESICL has been, for the first time, successfully and truly integrated in a planar substrate. In order to illustrate this fact, a wide band (100\% fractional bandwidth) bandpass eight cavities filter in ESICL has been designed and, using this new transition, integrated in a planar substrate. The filter exhibits a very high-quality response in the whole band of interest, with measured insertion losses around $0.16 \mathrm{~dB}$. The results presented in this paper are very promising, and open a wide range of possibilities to develop high-quality PCB-integrated devices in ESICL exhibiting: very low losses, wide working bandwidths, high stability, and immunity to interferences, cross-talk and dispersion.

\section{REFERENCES}

[1] D. Deslandes and K. Wu, "Integrated microstrip and rectangular waveguide in planar form," IEEE Microw. Wireless Compon. Lett., vol. 11, no. 2, pp. 68-70, Feb. 2001.

[2] D.-D. Zhang, L. Zhou, L.-S. Wu, L.-F. Qiu, W.-Y. Yin, and J.-F. Mao, "Novel bandpass filters by using cavity-loaded dielectric resonators in a substrate integrated waveguide," IEEE Trans. Microw. Theory Tech., vol. PP, no. 99, pp. 1-10, 2014.

[3] P. Chu, W. Hong, L. Dai, H. Tang, J. Chen, Z. Hao, X. Zhu, and $\mathrm{K}$. Wu, "A planar bandpass filter implemented with a hybrid structure of substrate integrated waveguide and coplanar waveguide," IEEE Trans. Microw. Theory Tech., vol. 62, no. 2, pp. 266-274, Feb. 2014.

[4] S. W. Wong, K. Wang, Z.-N. Chen, and Q.-X. Chu, "Design of millimeter-wave bandpass filter using electric coupling of substrate integrated waveguide (SIW)," IEEE Microw. Wireless Compon. Lett., vol. 24, no. 1, pp. 26-28, Jan. 2014.
[5] S. Sirci, J. Martinez, and V. Boria, "Low-loss 3-bit tunable SIW filter with PIN diodes and integrated bias network," in European Microwave Conference (EuMC), Oct. 2013, pp. 1211-1214.

[6] L. Xia, J. Xie, and G. Hua, "Design of a novel structure SIW filter," in IEEE MTT-S International Microwave Workshop Series on Millimeter Wave Wireless Technology and Applications (IMWS), Sept. 2012, pp. $1-4$.

[7] F. Mira, J. Mateu, S. Cogollos, and V. Boria, "Design of ultra-wideband substrate integrated waveguide (SIW) filters in zigzag topology," IEEE Microw. Wireless Compon. Lett., vol. 19, no. 5, pp. 281-283, May 2009.

[8] X.-P. Chen, W. Hong, T. Cui, J. Chen, and K. Wu, "Substrate integrated waveguide (SIW) linear phase filter," IEEE Microw. Wireless Compon. Lett., vol. 15 , no. 11 , pp. 787-789, Nov. 2005.

[9] H. J. Tang, W. Hong, Z. C. Hao, J. X. Chen, and K. Wu, "Optimal design of compact millimetre-wave SIW circular cavity filters," Electron. Lett., vol. 41, no. 19, pp. 1068-1069, Sept. 2005.

[10] Z.-C. Hao, W. Hong, J.-X. Chen, X.-P. Chen, and K. Wu, "Compact super-wide bandpass substrate integrated waveguide (SIW) filters," IEEE Trans. Microw. Theory Tech., vol. 53, no. 9, pp. 2968-2977, Sept. 2005.

[11] T. Y. Yang, W. Hong, and Y. Zhang, "Wideband millimeter-wave substrate integrated waveguide cavity-backed rectangular patch antenna," IEEE Antennas Wireless Propag. Lett., vol. 13, pp. 205-208, 2014.

[12] W. Han, F. Yang, and H. Zhou, "Slotted substrate integrated cavity antenna using TE330 mode with low profile and high gain," Electron. Lett., vol. 50, no. 7, pp. 488-490, Mar. 2014.

[13] H. Zhou and F. Aryanfar, "Millimeter-wave open ended SIW antenna with wide beam coverage," in IEEE Antennas and Propagation Society International Symposium (APSURSI), Jul. 2013, pp. 658-659.

[14] L.-R. Tan, R.-X. Wu, C.-Y. Wang, and Y. Poo, "Magnetically tunable ferrite loaded SIW antenna," IEEE Antennas Wireless Propag. Lett., vol. 12, pp. 273-275, 2013.

[15] J. Liu, D. Jackson, and Y. Long, "Substrate integrated waveguide (SIW) leaky-wave antenna with transverse slots," IEEE Trans. Antennas Propag., vol. 60, no. 1, pp. 20-29, Jan. 2012.

[16] H. Hizan, I. Hunter, and A. Abunjaileh, "Integrated SIW filter and microstrip antenna," in European Microwave Conference (EuMC), Sept. 2010, pp. 184-187.

[17] E. Diaz, A. Belenguer, H. Esteban, O. Monerris-Belda, and V. Boria, "A novel transition from microstrip to a substrate integrated waveguide with higher characteristic impedance," in IEEE MTT-S International Microwave Symposium Digest, 2013, pp. 1-4.

[18] E. Diaz Caballero, A. Belenguer, H. Esteban, and V. Boria, "Thru-reflectline calibration for substrate integrated waveguide devices with tapered microstrip transitions," Electron. Lett., vol. 49, no. 2, pp. 132-133, Jan. 2013.

[19] D. Deslandes, "Design equations for tapered microstrip-to-substrate integrated waveguide transitions," in IEEE MTT-S International Microwave Symposium Digest, 2010, pp. 704-707.

[20] J. Hui, W. Feng, and W. Che, "Balun bandpass filter based on multilayer substrate integrated waveguide power divider," Electron. Lett., vol. 48, no. 10, pp. 571-573, May 2012.

[21] Z.-Y. Zhang and K. Wu, "A broadband substrate integrated waveguide (SIW) planar balun," IEEE Microw. Wireless Compon. Lett., vol. 17, no. 12 , pp. 843-845, Dec. 2007.

[22] A. Ali, H. Aubert, N. Fonseca, and F. Coccetti, "Wideband two-layer SIW coupler: design and experiment," Electron. Lett., vol. 45, no. 13, pp. 687-689, Jun. 2009.

[23] A. Patrovsky, M. Daigle, and K. Wu, "Coupling mechanism in hybrid SIW-CPW forward couplers for millimeter-wave substrate integrated circuits," IEEE Trans. Microw. Theory Tech., vol. 56, no. 11, pp. 2594 2601, Nov. 2008

[24] T. Djerafi and K. Wu, "Super-compact substrate integrated waveguide cruciform directional coupler," IEEE Microw. Wireless Compon. Lett., vol. 17, no. 11, pp. 757-759, Nov. 2007.

[25] B. Liu, W. Hong, Y.-Q. Wang, Q.-H. Lai, and K. Wu, "Half mode substrate integrated waveguide (HMSIW) 3-dB coupler," IEEE Microw. Wireless Compon. Lett., vol. 17, no. 1, pp. 22-24, Jan. 2007.

[26] F. Xu and K. Wu, "Substrate integrated nonradiative dielectric waveguide structures directly fabricated on printed circuit boards and metallized dielectric layers," IEEE Trans. Microw. Theory Tech., vol. 59, no. 12, pp. 3076-3086, Dec. 2011.

[27] W. Hong, B. Liu, Y. Wang, Q. Lai, H. Tang, X. X. Yin, Y. D. Dong, Y. Zhang, and $\mathrm{K}$. Wu, "Half mode substrate integrated waveguide: A new guided wave structure for microwave and millimeter wave application," in Joint 31st International Conference on Infrared Millimeter Waves and 14th International Conference on Terahertz Electronics. IRMMW-THz, Sept. 2006, pp. 219-219. 
[28] Y. Cassivi and K. Wu, "Substrate integrated nonradiative dielectric waveguide," IEEE Microw. Wireless Compon. Lett., vol. 14, no. 3, pp. 89-91, 2004.

[29] D. Deslandes, M. Bozzi, P. Arcioni, and K. Wu, "Substrate integrated slab waveguide (SISW) for wideband microwave applications," in IEEE MTT-S International Microwave Symposium Digest, vol. 2, 2003, pp. 1103-1106.

[30] F. Gatti, M. Bozzi, L. Perregrini, K. Wu, and R. Bosisio, "A novel substrate integrated coaxial line (SICL) for wide-band applications," in 36th European Microwave Conference, Sept. 2006, pp. 1614-1617.

[31] P. Chu, W. Hong, L. Dai, H. Tang, Z. Hao, J. Chen, and K. Wu, "Wide stopband bandpass filter implemented with spur stepped impedance resonator and substrate integrated coaxial line technology," IEEE Microw. Wireless Compon. Lett., vol. 24, no. 4, pp. 218-220, Apr. 2014.

[32] P. Chu, W. Hong, J. X. Chen, and H. J. Tang, "A miniaturized bandpass filter implemented with substrate integrated coaxial line," Microw. Opt. Technol. Lett., vol. 55, no. 1, pp. 131-132, Jan. 2013.

[33] S. Jun-Yu, L. Qiang, W. Yong-Le, L. Yuan-An, L. Shu-Lan, Y. Cui-Ping, and L. Gan, "High-directivity single- and dual-band directional couplers based on substrate integrated coaxial line technology," in IEEE MTT-S International Microwave Symposium Digest (IMS), Jun. 2013, pp. 1-4.

[34] W. Liang and W. Hong, "Substrate integrated coaxial line $3 \mathrm{~dB}$ coupler," Electron. Lett., vol. 48, no. 1, pp. 35-36, Jan. 2012.

[35] F. Zhu, W. Hong, J.-X. Chen, and K. Wu, "Ultra-wideband single and dual baluns based on substrate integrated coaxial line technology," IEEE Trans. Microw. Theory Tech., vol. 60, no. 10, pp. 3062-3070, Oct. 2012.

[36] F. Gatti, M. Bozzi, L. Perregrini, K. Wu, and R. Bosisio, "A new wide-band six-port junction based on substrate integrated coaxial line (SICL) technology," in IEEE Mediterranean Electrotechnical Conference (MELECON), May 2006, pp. 367-370.

[37] A. Belenguer, H. Esteban, and V. Boria, "Novel empty substrate integrated waveguide for high-performance microwave integrated circuits," IEEE Trans. Microw. Theory Tech., vol. 62, no. 4, pp. 832-839, Apr. 2014.

[38] N. Jastram and D. Filipovic, "PCB-based prototyping of 3-D micromachined RF subsystems," IEEE Trans. Antennas Propag., vol. 62, no. 1, pp. 420-429, Jan 2014.

[39] D. M. Pozar, Microwave Engineering, 2nd ed. Hoboken, New Jersey: John Wiley \& Sons, Inc., 2005.

[40] X.-C. Zhu, W. Hong, K. Wu, K.-D. Wang, L.-S. Li, Z.-C. Hao, H.J. Tang, and J.-X. Chen, "Accurate characterization of attenuation constants of substrate integrated waveguide using resonator method," IEEE Microw. Wireless Compon. Lett., vol. 23, no. 12, pp. 677-679, Dec 2013

[41] A. Belenguer, A. L. Borja, H. Esteban, and V. E. Boria, "Estructura de transición de dos líneas de transmisión de señal en PCB," Patent Application ES Application No 201530 408, 03 27, 2015.

[42] J.-S. Hong and M. Lancaster, Microstrip filters for RF/microwave applications, ser. Wiley series in microwave and optical engineering. New York: John Wiley \& Sons, Inc., 2001.

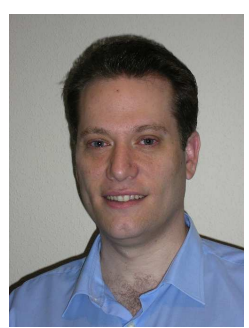

Angel Belenguer (M'04-SM'14) received his degree in telecommunications engineering from the Universidad Politécnica de Valencia (UPV), Spain, in 2000, and his Ph.D. degree, also from the UPV, in 2009. He joined the Universidad de Castilla-La Mancha in 2000, where he is now Profesor Titular de Universidad in the Departamento de Ingenieria Electrica, Electronica, Automatica y Comunicaciones. He has authored or co-authored more than 50 papers in peer-reviewed international journals and conference proceedings and frequently acts as a reviewer for several international technical publications. His research interests include methods in the frequency domain for the full-wave analysis of open-space and guided multiple scattering problems, the application of accelerated solvers or solving strategies (like grouping) to new problems or structures, EM metamaterials, and Substrate Integrated Waveguide (SIW) devices and their applications.

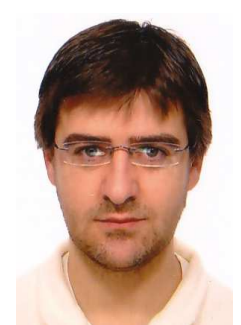

Alejandro L. Borja (M'15) received the M.Sc. degree in telecommunication engineering and the Ph.D. degree from the Universidad Politecnica de Valencia, Valencia, Spain, in 2004 and 2009, respectively. From 2005 to 2006, he was with the University of Birmingham, Birmingham, U.K. From 2007 to 2008 , he was with the Universite de Lille 1, Lille, France. Since 2009, he has been with the Universidad de Castilla-La Mancha, Spain, where he is an Assistant Lecturer. He has published more than 50 papers in peer-reviewed international journals and conference proceedings, and frequently acts as a reviewer for several technical publications. In 2012, he served as a Lead Guest Editor for a special issue of the International Journal of Antennas and Propagation. His research interests include EM metamaterials, substrate integrate waveguide, and reconfigurable devices and their applications in microwave and millimetric bands.

Dr. Borja was the recipient of the 2008 CST short paper award.

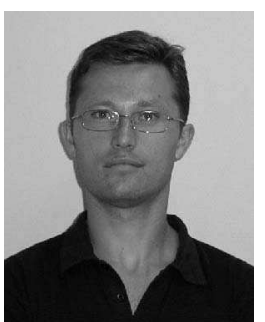

Héctor Esteban González (S'03-M'99-SM'14) received a degree in telecommunications engineering from the Universidad Politécnica de Valencia (UPV), Spain, in 1996, and a Ph.D. degree in 2002. He worked with the Joint Research Centre, European Commission, Ispra, Italy. In 1997, he was with the European Topic Centre on Soil (European Environment Agency). He rejoined the UPV in 1998. His research interests include methods for the full- wave analysis of open-space and guided multiple scattering problems, CAD design of microwave devices, electromagnetic characterization of dielectric and magnetic bodies, and the acceleration of electromagnetic analysis methods using the wavelets and the FMM.

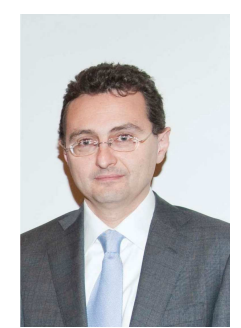

Vicente E. Boria (S'91-A'99-SM'02) was born in Valencia, Spain, on May 18, 1970. He received his Ingeniero de Telecomunicación degree (with firstclass honors) and the Doctor Ingeniero de Telecomunicación degree from the Universidad Politécnica de Valencia, Valencia, Spain, in 1993 and 1997, respectively. In 1993 he joined the Departamento de Comunicaciones, Universidad Politécnica de Valencia, where he has been Full Professor since 2003. In 1995 and 1996, he was holding a Spanish Trainee position with the European Space Research and Technology Centre, European Space Agency (ESTEC-ESA), Noordwijk, The Netherlands, where he was involved in the area of EM analysis and design of passive waveguide devices. He has authored or co-authored 7 chapters in technical textbooks, 75 papers in refereed international technical journals, and over 150 papers in international conference proceedings. His current research interests are focused on the analysis and automated design of passive components, left-handed and periodic structures, as well as on the simulation and measurement of power effects in passive waveguide systems. Dr. Boria has been a member of the IEEE Microwave Theory and Techniques Society (IEEE MTT-S) and the IEEE Antennas and Propagation Society (IEEE AP-S) since 1992. He is member of the Editorial Boards of the IEEE Transactions on Microwave Theory and Techniques, IEEE Microwave and Wireless Components Letters, Proceeding of the IET (Microwaves, Antennas and Propagation), IET Electronics Letters and Radio Science. Since 2013, he serves as Associate Editor of IEEE Microwave and Wireless Components Letters. He is also a member of the Technical Committees of the IEEEMTT International Microwave Symposium and of the European Microwave Conference. 